\title{
A ordem do discurso teatral: desordenando, reordenando, reverberando
}

\section{The order of theatrical discourse: scrambling, reordering, reverberating}

Mei Hua Soares ${ }^{1}$ 


\section{Resumo}

A partir de relato referente à apresentação da peça Zumbi or not Zumby (livre adaptação da paulistana Cia. Antropofágica para Arena conta Zumbi, do Teatro de Arena) realizada na Fundação CASA, unidade de Franco da Rocha, o presente artigo visa tecer considerações a respeito de como o discurso veiculado pelo teatro pode abordar assuntos relevantes - como o desterramento, a escravidão e a ausência de liberdade do negro no Brasil - que, no entanto, sofrem constante interdição junto a determinados públicos e contextos. Para tanto, foram mobilizados os conceitos de assimilação racista, de Darcy Ribeiro, de ordem discursiva, de Michel Foucault e de signo ideológico, de Mikhail Bakhtin.

Palavras-chave: Discurso teatral; teatro negro; signo ideológico.

\section{Abstract}

From reporting on the performance of the play Zumbi or not Zumby (a free adaptation of the Cia Antropofágica to Arena conta Zumbi, of the Arena Theatre) held at CASA Foundation, Franco da Rocha unit, this article intends to make considerations as to how the discourse conveyed by the theater can address relevant issues such as desterramento, slavery and the lack of freedom of the black in Brazil - which, however, suffer constant ban from certain public and contexts. Therefore, the concepts were mobilized racist assimilation, of Darcy Ribeiro, the discursive order of Michel Foucault and ideological sign of Mikhail Bakhtin.

Keywords: Theatrical discourse; black theater; ideological sign.

ISSN: 1414.5731

E-ISSN: 2358.6958

${ }^{1}$ Doutora em Linguagem e Educação pela Faculdade de Educação da Universidade de São Paulo (FEUSP) e Profa. do Curso de Comunicação Social da Faculdade Cásper Líbero (FCL), São Paulo, SP, Brasil.

meihuasoares@gmail.com 
Negro no cativeiro

Fez a corrente arrebentar $[\ldots]$

Bota o negro lá no tronco

Que a cultura vem na dor

O negro é muito mais valente

Que a chibata do feitor [...]

Cantiga de capoeira

Ou bem há democracia para todos, ou não há democracia para ninguém, porque à opressão do negro condenado à dignidade de lutador da liberdade corresponde o opróbrio do branco posto no papel de opressor dentro de sua própria sociedade.

Darcy Ribeiro

(O povo brasileiro)

Em uma sociedade como a nossa, conhecemos, é certo, procedimentos de exclusão. O mais evidente, o mais familiar também, é a interdição. Sabe-se bem que não se pode falar de tudo em qualquer circunstância, que qualquer um, enfim, não pode falar de qualquer coisa.

Michel Foucault (A ordem do discurso)

Em 2009, acompanhando um grupo de teatro (PY, núcleo de formação da Cia. Antropofágica), cujo projeto fora contemplado pelo Programa Municipal de Fomento ao Teatro para a Cidade de São Paulo, em apresentação numa das unidades da Fundação CASA - instituição para menores infratores - localizada em Franco da Rocha (SP), pude, pela primeira vez, ter acesso ao local restrito a internos (jovens em faixa etária semelhante a de meus alunos da escola pública estadual) e funcionários.

A convite de uma das educadoras, os artistas participariam de um evento comemorativo da unidade apresentando uma peça que o grupo já levava a algumas escolas públicas gratuitamente. A peça em questão era uma adaptação do espetáculo Arena conta Zumbi, musical de Augusto Boal, Gianfrancesco Guarnieri e Edu Lobo, de 1965: Zumbi or not Zumby. A experiência, misto de curiosidade, receio e angústia, foi tão impactante que, à época, não consegui escrever sequer uma linha (a intenção era ao menos registrar algo por escrito). Os fatores que levaram à mudez foram diversos. A realidade, por vezes, se sobrepõe às representações tornando-as quase impossíveis. No entanto, uma das coisas que mais se revelou surpreendente, e é esse o mote do presente artigo, foi o alcance inextrincável do discurso veiculado pela linguagem teatral, a que chamaremos aqui de discurso teatral, mais especificamente, em contextos de interdição. Para discorrer sobre ele, será feita breve descrição-relato do dia da apresentação, seguido de reflexões fundamentadas em textos de Darcy Ribeiro, Michel Foucault, Mikhail Bakhtin, José Luiz Fiorin e Augusto Boal. 


\section{"Abacateiro, serás meu parceiro solitário"; refazendo tudo: relato sobre apresen- tação de Zumbi or not Zumby na Fundação CASA}

"Não sei se devo ir, mas quero". Esse era o pensamento constante após o convite dos antropófagos do PY, o grupo de formação de atores e atrizes da Cia. Antropofágica. Eu iria apenas para acompanhá-los, ou seja, tarefa muito mais fácil de desempenhar que a dos artistas que, em meio a sensações controversas, precisariam ainda sustentar a apresentação do espetáculo. No dia anterior à apresentação, não conseguira dormir, pensando em informações sobre rebeliões ocorridas em outros momentos em outras unidades. Lembrei-me do relato de um ex-funcionário da Fundação, quando ainda FEBEM, mencionando as atrocidades cometidas, tanto pelos internos, como também por alguns agentes. Pensava ainda em alguns de meus alunos da escola pública, aqueles que frequentavam as aulas em regime de liberdade assistida, e em outros tantos que cometiam atos que possivelmente poderiam confiná-los nessa mesma instituição. Ainda nessa mesma noite insone, dentro do caos mental, buscando concatenar pensamentos soltos sem muito sucesso, o quebra-cabeça que se formava era o da imagem do sujeito-assujeitado, protagonista anti-heroico da tragédia do confinamento adolescente no Brasil. Sujeito esse pobre, negro ou mestiço e, ao que parece, cada vez mais novo e mais comprimido pela opressão e pela violência que o circunda. O sono custava a vir depois dessa constatação e fui reler textos de literatura marginal publicados em três edições da Revista Caros Amigos, organizadas pelo escritor Ferréz. A maior parte dos discursos que emanavam dos textos narrativos e poéticos corroborava essas impressões. O que não é novidade para ninguém.

Logo cedo, nos encontramos em um ponto comum a todos que para lá se dirigiam. Estradinha sinuosa de asfalto, casas simples, casebres. Periferias. Chegando em Franco da Rocha, entretanto, o cenário era quase interiorano. Ruas de terra, pouco movimento de carros e de pessoas, mato. Após alguns desvios e erros, chegamos ao complexo da Fundação CASA. O muro de concreto, muito alto, contrastava com a paisagem bucólica, com as árvores frondosas que ladeavam a entrada. Estacionei o carro embaixo de um grande abacateiro que oferecia uma boa sombra.

Recordo esse momento da saída de nossos veículos. Medo significativo. Vontade de dar meia volta, de não levar adiante a visita. Essa sensação me fez lembrar, por sua vez, um comentário proferido por um dos integrantes do mesmo grupo de formação, quando de sua apresentação na escola pública em que leciono: "Nossa... parece um presídio, né?". Centros socioeducativos e escolas assemelhando-se a presídios. Também não é novidade para ninguém.

O diretor do grupo, Thiago Reis Vasconcelos, reuniu a todos para fornecer algumas "orientações gerais". Tendo já lecionado e trabalhado junto a adolescentes em outras unidades da fundação, as recomendações davam ainda mais pavor em quem não sabia o que estava por vir.

Em seguida, a dúvida era como seria a revista. Haveria a necessidade da revista íntima? Se sim, por mais descolados que fôssemos, seria constrangedor. Mas se fosse preciso... Logo a educadora responsável pelo convite apareceu para nos receber. Muito gentil, acolheu-nos de modo ímpar, deixando-nos mais à vontade. Por sermos "convidados especiais", não precisaríamos passar pela revista íntima, somente por 
uma mais geral. Atravessando os portões de ferro (dois), chegamos ao recinto em que ficavam alocadas as salas dos funcionários e educadores. O ambiente é arborizado, há flores plantadas, uma pequena biblioteca, sala de professores, banheiros. Pude olhar de relance os exemplares disponíveis para leitura. Não há muitos títulos e, confirmei depois, nem toda literatura é permitida. Nós mulheres, que apenas assistiríamos à apresentação, por recomendação da educadora, colocamos aventais para cobrir o corpo. Aliás, o corpo (o seu cerceamento, o seu aprisionamento, a sua contenção) é elemento-chave para compreensão desse contexto.

Os atores e atrizes colocaram seus figurinos e nos direcionamos para o local em que ficavam os meninos internos. Mais um último portão duplo de ferro e adentramos o espaço. Casas esparsas, rodeadas por árvores, ambiente simples, quase rural. Numa dessas casas, uma central, aconteceria a apresentação. Fomos conduzidos ao centro da sala. Nela, estavam dispostas várias cadeiras onde o público se acomodaria.

O grupo organizou uma meia lua de cadeiras na parte em que os artistas apresentariam, de acordo com a disposição do teatro de Boal, de arena, predispondo atores e atrizes a encenar de acordo com o sistema coringa. Sentei-me em uma das cadeiras. Enquanto os artistas arrumavam seus últimos objetos de cena, alguns poucos meninos ocuparam cadeiras da plateia. Com olhares um tanto desconfiados, nosso público timidamente chegava.

Quando recordo desse momento de reconhecimento entre plateia e artistas na Fundação, o corpo dos meninos, seus olhares, suas posturas, seus andares remetem ao que Paul Zumthor, analisando elementos associados à performance e à recepção de leitura, afirma com relação à materialidade do corpo e às ações por eles simbolicamente sofridas:

Meu corpo é a materialização daquilo que me é próprio, realidade vivida e que determina minha relação com o mundo. Dotado de uma significação incomparável, ele existe à imagem de meu ser: é ele que eu vivo, possuo e sou, para o melhor e o pior. Conjunto de tecidos e de órgãos, suporte da vida psíquica, sofrendo também as pressões do social, do institucional, do jurídico, os quais, sem dúvida, pervertem nele seu impulso primeiro (Zumthor, 2007, pp.23-24).

A previsibilidade de movimentos e a ordenação, ressaltadas pelo uso dos uniformes, apontavam para uma linguagem corporal própria do confinamento.

Já os olhares, apesar de igualmente condicionados, ainda revelavam resquícios de espontaneidade.

A apresentação teve início. Apesar de ter assistido a inúmeras apresentações e ensaios da peça, nunca o texto Arena conta Zumbi - Zumbi or not Zumby foi tão especial. Cada palavra dita, cada canto-lamento, cada inflexão de voz, cada gesto adquiriram contundência e veracidade. Uma dolorosa veracidade.

Alguns trechos do texto eram ainda mais significativos: 
É Zambi² no açoite, êi, êi, é Zambi

E Zambi, tui, tui, tui, tui, é Zambi

É Zambi na noite, êi, êi, é Zambi

E Zambi, tui, tui, tui, tui, é Zambi

O número de mortos na campanha de Palmares - que durou cerca de um século - é insignificante diante do número de mortos que se avolumam, ano a ano, na campanha incessante dos que lutam pela liberdade. Ao contar Zambi, prestamos uma homenagem a todos aqueles que, através dos tempos, dignificam o ser humano, empenhados na conquista de uma terra da amizade onde o homem ajuda o homem.

Quando essa fala ecoou em cena, o silêncio pareceu ficar ainda mais expressivo. Nosso público, aos poucos, aumentava durante a encenação. Alguns garotos que ouviam do lado de fora, se aproximaram um pouco mais. Outros, que já estavam no interior da sala, se levantaram e andavam de um lado a outro, respondendo corporalmente às inquietações geradas. Os cantos eram recebidos com maior atenção:

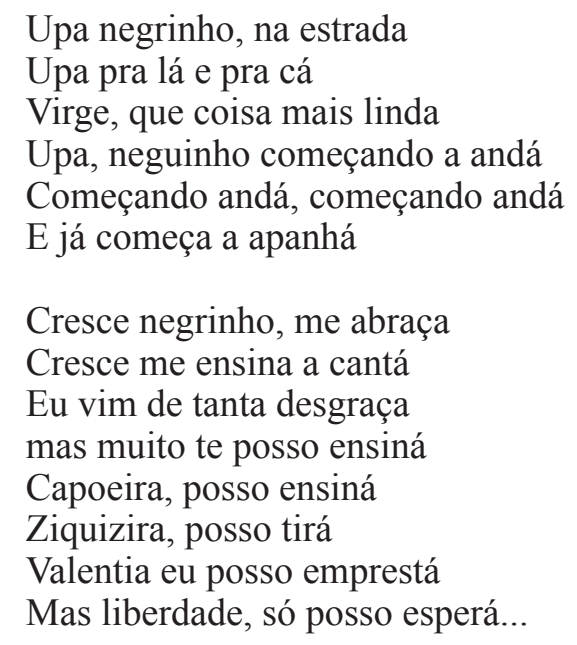

Ao longo da apresentação, mediante o desenrolar das cenas teatrais, um clima de experiência conjunta se instaurou. Se os soldados combatentes voltavam dos campos de batalha emudecidos, segundo Walter Benjamin (1994, p.198),

a história narrada-encenada em situação de aprisionamento na Fundação parecia adquirir contornos importantes, ainda que extremamente tensos, de experiência comunicável e válida.

Mas toda arte envolve risco. Durante os cantos finais da peça, a tensão parece ter pairado no ar mais fortemente. Especialmente diante da fala de Zambi seguida do coro:

ZAMBI - Eu vivi nas cidades no tempo das desordem. Eu vivi no meio da minha gente no tempo da revolta. Assim passei os tempo que me deram pra vivê. Eu me levantei com a minha gente, comi minha comida no meio da batalha. Amei sem ter cuidado... Olhei tudo que via, sem tempo de bem ver... Assim passei os

\footnotetext{
2 Na peça, o autor optou em manter o nome original de Zumbi dos Palmares, Zambi, do africano kimbundu "nzambi", que significa "deus".
} 
tempo que me deram pra viver. A voz da minha gente se levantou e minha voz junto com a dela. Minha voz não pode muito, mas gritá eu bem gritei. Tenho certeza que os donos dessas terra e Sesmaria ficaria mais contente se não ouvisse a minha voz... Assim passei os tempo que me deram pra viver.

\section{CORO}

É um tempo de guerra, é um tempo sem sol.

Sem sol, sem sol, sem dó.

E você que me prossegue

e vai ser feliz a terra,

lembre bem do nosso tempo,

deste tempo que é de guerra.

É um tempo...

Veja bem que preparando

o caminho da amizade.

Não podemos ser amigos

Ao mal vamos dar maldade 3

É um tempo...

Se você chegar a ver

essa terra da amizade,

onde o homem ajuda o homem,

pense em nós só com bondade.

Os personagens - negros fugidos, quilombolas - exigiam ainda mais reflexão. Todos éramos herdeiros desse desterramento negro. Somos desterrados em nossa própria terra, segundo Sérgio Buarque de Holanda (1936). Mas ali, alguns sentiam no corpo, na carne, essa pesada herança, ou melhor, essa dívida histórica ainda não paga, não redimida.

A apresentação foi aplaudida pelo público presente, formado essencialmente pelos internos, mas também por funcionários, educadores e pelo diretor da unidade. Um dos jovens, em nítido tom de liderança, agradeceu ao grupo em nome de todos. Um agradecimento sucinto, marcado por expressões peculiares ("senhor", "senhora", em falas rápidas e monocórdias), próprias do linguajar de obediência. Mas visivelmente sincero. A meu ver, uma das poucas devolutivas possíveis naquele momento. Diante da interdição (consciente e inconsciente, direta e indireta), qualquer vislumbre de comunicação adquire força e sentido.

Ao término da peça, alguns poucos rapazes vieram falar conosco. Empolgados, ressaltavam que estavam a escrever poemas, textos. Queriam mostrar suas produções, mas não puderam.

\footnotetext{
${ }^{3}$ Quanto a essa complexa passagem, poderíamos acrescentar uma passagem do livro Teatro do oprimido e outras poéticas políticas, em que Augusto Boal discorre sobre as difíceis relações entre opressores e oprimidos e sobre a necessidade de distinguir uns dos outros: "Não podemos conceder perdão e oferecer nossa amizade a quem escolheu o proveito próprio às custas da infelicidade dos outros, e decidiu gozar a própria vida ao custo da morte alheia. Aqueles que querem a todos perdoar, 'ver a questão de todos os lados', aqueles que tentam justificar as razões dos opressores, são os imobilistas do mundo" (Boal, ${ }^{2005}$, p. $^{25}$ ). Importante salientar, no entanto, a ressalva que 0 autor faz, nesse mesmo texto, sobre quem são os opressores e oprimidos: "Oprimidos e opressores não podem ser candidamente confundidos com anjos
}

e demônios. Quase não existem em estado puro, nem uns nem outros. Desde o início do meu trabalho com o Teatro do Oprimido fui levado, em muitas ocasiões, a trabalhar com opressores no meio de oprimidos, e também com alguns oprimidos que oprimiam." (Boal, ${ }^{2005}$, p. ${ }^{23}$ ). Esses trechos apontam para a crítica de uma política de reconciliação que apenas vise acalmar os ânimos, pacificá-los, sem nada solucionar. 
Também nós não pudemos abrir um debate para termos acesso às impressões do público sobre a peça. Logo fomos conduzidos para fora das dependências da fundação e da convivência com os internos. Os educadores chegaram a preparar um amistoso lanche, porém, gostaria muito era de ter proseado um pouco mais com os garotos.

Retornando ao estacionamento para além dos altos muros e das concertinas, pudemos respirar um pouco mais aliviados. Mais tristes também. A realidade por vezes se revela indizível.

$\mathrm{E}$, do lado de fora, o frondoso abacateiro, possivelmente transfundindo a tensão de nossos corpos e mentes ao longo do processo, arrebentou o para-brisa de meu carro ao deixar cair um de seus frutos de uma altura considerável. A metáfora do fruto que escapa da árvore e ocasiona violento golpe deixa a pergunta: a violência da queda depende da altura de que despenca o fruto? A violência dos jovens depende do contexto omisso e da barbárie a que são submetidos?

\section{A questão negra presente no texto, na peça e na Fundação: reverberações}

O projeto da Cia. Antropofágica, à época da apresentação relatada, subsidiado por políticas públicas voltadas à manutenção de ações e processos de grupos de teatro com trabalho continuado, referia-se à abordagem da história do Brasil em uma trilogia de peças. Em 2009, a companhia voltava sua atenção para o estudo do Brasilcolônia, da exploração da mão-de-obra escrava e da dizimação de índios. O homem livre e suas relações com as estruturas escravocratas também foi mote de pesquisa por parte do grupo. Para além dos espetáculos, diversos ciclos de estudo, palestras, oficinas foram por eles realizados.

Ao Núcleo PY, braço de formação da companhia, coube a tarefa de apresentar a peça adaptada do original Arena conta Zumbi, cujo texto trata essencialmente dos quilombolas, da resistência negra frente à escravidão, da história de Zumbi dos Palmares, da ausência de liberdade cravada nas raízes brasileiras.

A encenação realizada na Fundação CASA, nesse sentido, surge como um paradoxo aparentemente intransponível entre ficção e realidade: falar cenicamente de liberdade dentro de uma fundação destinada à recuperação de menores infratores que têm suas liberdades tolhidas por um regime de aprisionamento. Outra amarga constatação foi falar sobre a questão da escravidão negra no Brasil para jovens internos majoritariamente de descendência negra, cabocla ou mestiça. Nesse contexto, a história narrada ao longo da peça, não só adquire outro sentido como reforça o quão pouco o panorama histórico racial avançou em direção à valorização e equidade.

A perda de suas raízes, de sua identidade, de seu lugar de pertencimento fez do negro brasileiro um permanente lutador em busca da legitimidade que the foi historicamente negada:

[...] a luta mais árdua do negro africano e de seus descendentes brasileiros foi, e ainda é, a conquista de um lugar e de um papel de participante legítimo na sociedade nacional. Nela se viu incorporado à força. Ajudou a construí-la e, nesse esforço, se desfez, mas, ao fim, só nela sabia viver, em razão de sua total desafricanização (Ribeiro, 2006, p. 202). 
Essa busca, no entanto, por vezes desencadeou cooptação da identidade negra por parte da mídia e da indústria cultural. Darcy Ribeiro, em O povo brasileiro, analisa o racismo contra o negro sob uma perspectiva, nomeada por ele como "racismo assimilacionista" ${ }^{4}$, ainda em voga no que diz respeito à representação do negro e da negra social e culturalmente no Brasil:

O aspecto mais perverso do racismo assimilacionista é que ele dá de si uma imagem de maior sociabilidade, quando, de fato, desarma o negro para lutar contra a pobreza que lhe é imposta, e dissimula as condições de terrível violência a que é submetido. É de assinalar, porém, que a ideologia assimilacionista da chamada democracia racial afeta principalmente os intelectuais negros. Conduzindo-os a campanhas de conscientização do negro para a conciliação social e para o combate ao ódio e ao ressentimento do negro. Seu objetivo ilusório é criar condições de convivência em que o negro possa aproveitar as linhas de capilaridade social para ascender através da adoção explícita das formas de conduta e de etiqueta dos brancos bem-sucedidos (Ribeiro, 2006, p. 208).

Com relação à problemática da representação na literatura - do negro, mas também do pobre, da mulher e de todas as minorias marginalizadas - por exemplo, Regina Dalcastagné salienta o problema da representatividade e a dificuldade do acesso à voz que "não é suprida pela boa vontade daqueles que monopolizam os lugares de fala" (Dalcastagné, 2008, p.79). Ou seja, além de questionarmos a imagem (estereotipada, embranquecida, exótica) que aparece nas obras (literárias, teatrais, televisivas etc.) do negro, poderíamos apontar não só o veto por ele sofrido, no que diz respeito ao acesso à voz e à legitimação, mas também colocar em xeque alguns discursos, por vezes bem intencionados, que buscam falar em nome deles.

Pensando sob esse viés e considerando a dimensão pedagógica do processo (apropriada a uma fundação supostamente voltada à reinserção de adolescentes e de apoio socioeducativo), os jovens internos que, num primeiro momento, assistiram à peça, poderiam, a partir desse estímulo e de outras propostas, produzir seus próprios textos, escrever e atuar, criar poéticas orgânicas, construir suas próprias histórias. Fictícias e reais.

\section{O alcance do discurso veiculado em cenas de teatro}

Outra reflexão decorrente da supracitada apresentação foi a constatação da existência de "procedimentos de controle e de delimitação do discurso" (Foucault, 1970) ainda mais exacerbados no contexto de confinamento. Embora a afirmação seja aparentemente óbvia, dadas as circunstâncias de controle e docilização dos corpos, de violência física e simbólica envolvidas nas situações de privação de liberdade, gostaria de insistir na reflexão para tentar nela buscar o seu reverso.

\footnotetext{
4 "Prevalece em todo o Brasil, uma expectativa assimilacionista, que leva os brasileiros a supor e desejar que os negros desapareçam pela branquização progressiva". (Ribeiro, 2006, p. 206.)
} 
Michel Foucault, em sua aula transformada em livro, A ordem do discurso (1970), explana a respeito: "[...] ninguém entrará na ordem do discurso se não satisfizer a certas exigências ou se não for, de início, qualificado para fazê-lo" (Foucault, 1996 [1970], p. 37). Ou seja, o sujeito que se propõe a adentrar o terreno discursivo, perceberá, especialmente em algumas situações comunicativas e em contextos específicos, que forças coercitivas exigem determinadas qualificações do enunciador, 0 que significa, em suma, que a ordem discursiva existente determina de um modo ou de outro quem está autorizado a proferir este ou aquele discurso. Isso revela a complexidade (e, em muitos casos, perversidade) existente no processo de legitimação discursiva. A divisão entre aqueles que estão aptos a discursar sobre tais e tais assuntos e aqueles a quem é negado o acesso discursivo já estabelece, de antemão, a importância dos discursos. Provavelmente por ser ele o responsável pela disseminação - confirmação, questionamento, ruptura - das ideologias 5 . Há, portanto, um receio com relação ao que pode advir da manipulação discursiva, ainda mais da que escapa à lógica dos discursos hegemônicos ${ }^{6}$. E esse risco, inerente ao ato comunicativo (que, segundo o linguista José Luís Fiorin, também é uma forma de ação7) está envolvido, em maior ou menor grau, em todas as situações discursivas, especialmente as que envolvem grande quantidade de pessoas ou situações de interação permeadas por outros tipos de coerção.

A apresentação da peça envolvia uma sobreposição de discursos veiculados por intermédio da linguagem teatral, híbrida por excelência (verbal, musical, gestual, visual etc.) e culminou com uma estranha comoção, da parte dos artistas que apresentavam, e possível identificação, por parte dos que os assistiam. Essa sensação de que algo foi válido enquanto experiência comum, coletiva, ressignifica o(s) discurso(s) tornando-o(s) capazes de propiciar um acontecimento discursivo e, consequentemente, efeitos:

Se os discursos devem ser tratados, antes, como conjuntos de acontecimentos discursivos, que estatuto convém dar a esta noção de acontecimento que foi tão raramente levada em consideração pelos filósofos? Certamente o acontecimento não é nem substância nem acidente, nem qualidade, nem processo; o acontecimento não é da ordem dos corpos.

Entretanto, ele não é imaterial; é sempre no âmbito da materialidade que ele se efetiva, que é efeito [...] (Foucault, 1996 [1970], p.57).

Na perspectiva benjaminiana, poderíamos aproximar esse acontecimento discursivo da experiência ${ }^{8}$ proporcionada pelo compartilhamento de narrativas, especialmente as mais próximas da tradição oral, passadas de geração em geração no

\footnotetext{
5 "A aprendizagem linguística, que é a aprendizagem de um discurso, cria uma consciência verbal, que une cada indivíduo aos membros de seu grupo social. Por isso, a aprendizagem está estreitamente veiculada à produção de uma identidade ideológica, que é o papel que o indivíduo exerce no interior de uma formação social" (Fiorin, 2007, p. 44).

6 "Há, sem dúvida, em nossa sociedade e, imagino, em todas as outras, mas segundo um perfil e facetas diferentes, uma profunda logofobia, uma espécie de temor surdo desses acontecimentos, dessa massa de coisas ditas, do surgir de todos esses enunciados, de tudo o que possa haver aí de violento, de descontínuo, de combativo, de desordem, também, e de perigoso, desse grande zumbido incessante e desordenado do discurso" (Foucault,1996 [1970], p. 50.)
}

\footnotetext{
7 "Comunicar é também agir num sentido mais amplo. Quando um enunciador reproduz em seu discurso elementos da formação discursiva dominante, de certa forma, contribui para reforçar as estruturas de dominação. Se vale de outras formações discursivas, ajuda a colocar em xeque as estruturas sociais. [...] Sem pretender que o discurso possa transformar o mundo, pode-se dizer que a linguagem pode ser instrumento de libertação ou de opressão, de mudança ou de conservação" (Fiorin, 2007, p.74).

8 "A experiência que passa de pessoa a pessoa é a fonte a que recorreram todos os narradores. $E$, entre as narrativas escritas, as melhores são as que menos se distinguem das histórias orais contadas pelos inúmeros narradores anônimos" (Benjamin, 1994, p.198)
} 
passado (e entendidas pelo filósofo como extintas ou empobrecidas).

Já Fiorin discorre sobre a consciência verbal que une cada indivíduo aos membros de seu grupo social. Poderíamos falar, a partir da experiência relatada, na criação de uma consciência comum coletiva (ainda que efêmera) gerada por um discurso veiculado em linguagem teatral, cênica. Apesar de momentânea, a identificação pode se revelar potente se pensada enquanto experiência ou dispositivo disparador.

Importante salientar o gênero de veiculação, o suporte do discurso. Trata-se de uma peça teatral. Se fosse um debate, talvez não acontecesse, não fosse autorizado. Mediante um manifesto ou uma intervenção, as tensões seriam tão aparentes que impossibilitariam a troca, o acontecimento e a experiência.

Outro dado fundamental é a aparente isenção discursiva por parte dos artistas que se propuseram a encenar, uma espécie de "resguardo teatral discursivo". Obviamente, há a escolha por essa ou aquela peça, por esse ou aquele texto, por essa estética em detrimento de outra. A escolha em si já determina posicionamentos. No entanto, se o enunciador de um discurso não é seu detentor e nem mesmo seu criador, também o artista que encena aparenta não ser o responsável primeiro pelos discursos que já existem, o que, no caso da experiência relatada, e de tantas outras ${ }^{9}$, pode ser um "trunfo". Arena conta Zumbi não foi escrita pelos atores e atrizes que lá se apresentavam, não foi criada pelo diretor. A peça foi escrita em plena ditadura civil-militar, foi elaborada em outro contexto sociopolítico e refere-se a um momento histórico ainda anterior. À época da censura militar, falar dos negros quilombolas já se apresentava como possibilidade de tratar de liberdade por intermédio de alusões, de metáforas, fazendo menção à histórica ausência daquela. Na apresentação aos jovens internos da Fundação CASA, local em que é perceptível a existência do controle permanente - de discursos, de falas, de ações, de posicionamentos - a peça se revelou enquanto desdobramento metafórico e histórico duplicado. E os discursos - ali curiosa e momentaneamente vazados, permitidos porque teatro, porque ficção, porque revestidos de sons, imagens, gestos, música, encenação - puderam, ainda que por pouco tempo, circular livre e poeticamente entre os presentes.

\section{Algumas considerações}

Tanto o relato como as reflexões a ele relacionadas visam enfatizar o caráter provocador e quiçá formativo do teatro. Decerto esses jovens deveriam não só poder assistir a peças, como também criar, atuar, debater sobre as questões que surgem em cena e questões que dizem respeito a ele e a sua história. Num contexto em que até os livros são escassos, as leituras controladas, o direito à palavra vetado, a apresentação mencionada aparece como uma fagulha de diálogo. Um início. Ainda muito

9 É conhecida a potência e o "desarmamento" envolvidos nas ações que circulam por intermédio da linguagem teatral. Não é regra, mas sabemos que, em geral, as ações artísticas, mesmo quando reivindicatórias ou incitativas, são menos passíveis de respostas truculentas. 
distante do acesso à voz, da possibilidade de proferir com legitimidade seus próprios discursos, construir suas próprias cenas - teatrais, sociais, políticas.

É sabido que o alcance do teatro, assim como os seus desdobramentos, é imprevisível. A sua recepção, mesmo quando fortemente direcionada pelo enredo da peça, não é determinada. Os signos envolvidos na cena teatral são diversos, complexos, dinâmicos. Mas a sua discursividade pode fornecer sustentação para que diferentes percepções (e reflexões) emerjam no discurso interior ${ }^{10}$ em outros contextos de interação. Isso pode contribuir como instrumentação, para que consigam lidar com as pressões exercidas por discursos dominantes que constantemente visam reafirmar sua anulação enquanto sujeitos.

Nesse sentido, a ordem do discurso teatral pode desestabilizar concepções ideológicas mantidas por discursos dominantes excludentes numa espécie de ordem que desordena, ou melhor, que reordena oferecendo outros parâmetros e refrações. Os mesmos signos ideológicos dominantes, se inseridos e manipulados com outros fins dentro da cena teatral, podem se revelar subversivos à ordem discursiva de origem $^{11}$, apresentando-se de maneira inversa, dada a dialética interna do signo ${ }^{12}$. 0 hibridismo, próprio da linguagem teatral, acaba por imprimir fluidez aos discursos que veicula. Há na cena teatral ainda o revestimento estético que possibilita que seus signos adentrem esferas que possivelmente se mostrariam restritas a outros suportes discursivos.

O que se espera, no entanto, diante do panorama crítico em que se encontram os jovens encarcerados - e do legado teatral e político deixado por Augusto Boal e pelo Teatro de Arena, sobre a história negra, sobre a liberdade e sobre esses tristes "tempo(s) de guerra, tempo(s) sem sol e sem dó" -, é conseguir, ao menos, fazer com que cenas, narrativas e discursos que escapam à pacificação ideológica também possam circular entre os muros físicos e simbólicos que isolam esses mesmos jovens.

\section{Referências}

BAKHTIN, Mikhail (VOLOCHÍNOV). Marxismo e filosofia da linguagem: problemas fundamentais do método sociológico da linguagem. São Paulo: Hucitec, 2006.

BOAL, Augusto. Teatro do oprimido e outras poéticas políticas. Rio de Janeiro: Civilização Brasileira, 2005.

\footnotetext{
10 "Os processos de compreensão de todos os fenômenos ideológicos (um quadro, uma peça musical, um ritual ou um comportamento humano) não podem operar sem a participação do discurso interior. Todas as manifestações da criação ideológica - todos os signos não verbais - banham-se no discurso e não podem ser nem totalmente isoladas nem totalmente separadas dele" (Bakhtin, ${ }^{2006}$, p. ${ }^{38}$ ).

${ }^{11}$ Embora esse fenômeno não seja tão perceptível na peça aqui relatada, em outros espetáculos da Cia. Antropofágica, isso é muito latente. Um mesmo discurso, deslocado de seu contexto e inserido em outro, pode se apresentar completamente inverso ao seu sentido primeiro.
}

\footnotetext{
12 "Na realidade, todo signo ideológico vivo tem, como Jano, duas faces. Toda crítica viva pode tornar-se elogio, toda verdade viva pode parecer para alguns a maior das mentiras. Esta dialética interna do signo não se revela inteiramente a não ser em épocas de crise social e de comoção revolucionária" (Bakhtin, 2006, p.48, grifos do autor).
} 
DALCASTAGNĖ, Regina (org.). Vozes nas sombras: representação e legitimidade na narrativa contemporânea". In: Ver e imaginar o outro - alteridade, desigualdade, violência na literatura brasileira contemporânea. Vinhedo (SP): Horizonte, 2008.

FIORIN, José Luiz. Linguagem e Ideologia. São Paulo: Ática, 2004.

FOUCAULT, Michel. A ordem do discurso. São Paulo: Loyola, 2006.

RIBEIRO, Darcy. O povo brasileiro: a formação e o sentido do Brasil. São Paulo: Companhia das Letras, 2006.

ZUMTHOR, Paul. Performance, recepção e leitura. São Paulo: Cosac Naify, 2007.

Recebido em: 30/04/2015

Aprovado em: 02/07/2015 